DOI: https://doi.org/10.24127/ajpm.v10i4.4198

\title{
PENGEMBANGAN VIDEO PEMBELAJARAN BERBASIS GEOGEBRA MATERI BANGUN RUANG SISI DATAR PADA PEMBELAJARAN VIRTUAL
}

\author{
La Ode Sirad ${ }^{1 *}$, Arbain $^{2}$ \\ ${ }^{1 *, 2}$ Universitas Sembilanbelas November Kolaka, Kolaka, Indonesia \\ *Corresponding author. \\ E-mail: $\quad \frac{\text { laodesirad.usnkolaka@gmail.com }}{\text { abughazwanalhasan@gmail.com }}{ }^{2)}$
}

Received 06 September 2021; Received in revised form 17 November 2021; Accepted 22 December 2021

\begin{abstract}
Abstrak
Penelitian ini bertujuan untuk mengahasilkan video pembelajaran berbasis geogebra yang valid, praktis dan efektif. Model pengembangan yang digunakan adalah model Plomp yang terdari atas lima fase, yaitu investigasi awal; desain; konstruksi; uji produk, evaluasi, dan revisi; dan implementasi. Video hasil produksi digunakan sebagai sumber belajar dalam kelas virtual google classroom. Video pembelajaran divalidasi oleh dua orang ahli dengan melakukan penilaian pada aspek kelayakan isi dan kelayakan tampilan. Hasil validasi menyatakan video pembelajaran valid dengan kategori sangat baik. Video diimplementasikan sebagai sumber belajar pada proses pembelajaran secara virtual di SMPN 6 Buton tengah. Respon siswa terhadap penggunaan video sangat positif. Hasil angket respon siswa menunjukkan video sangat praktis. Penerapan video berdampak positif terhadap capaian hasil belajar siswa. video pembelajaran berbasis geogebra memudahkan siswa dalam memvisualisasikan gambar tiga dimensi sehingga meningkatkan pemahaman terhadap konsep bangun ruang. Hasil penilaian efektifitas menyatakan video sangat efektif.
\end{abstract}

Kata Kunci : Bangun ruang; ruang kelas virtual; video berbasis geogebra.

\begin{abstract}
This study aims to produce valid, practical and effective geogebra-based learning videos. The development model used is the Plomp model which consists of five phases, namely initial investigation; design; construction; product testing, evaluation, and revision; and implementation. The video production is used as a learning resource in the virtual google classroom. The learning videos were validated by two experts by assessing the aspects that matched their appearance. The results of the validation state that the learning video is valid with a very good category. Video is implemented as a learning resource in the virtual learning process at SMPN 6 Buton Tengah. Student response to the use of video was very positive. The results of the student response questionnaire showed a very practical video. The application of video has a positive impact on the achievement of student learning outcomes. Geogebra-based learning videos make it easier for students to visualize three-dimensional images so as to increase understanding of the concept of building space. The results of the effectiveness assessment stated that the video was very effective.
\end{abstract}

Keywords : Geogebra based videos; geometry; virtual classroom.

This is an open acces article under the Creative Commons Attribution 4.0 International License

\section{PENDAHULUAN}

Membekali pelajar dengan pemahaman konsep matematika saat ini dan masa mendatang merupakan tantangan yang signifikan. Tantangan- tantangan ini telah diperparah oleh merebaknya Covid-19 belakangan ini. Pemberlakuan jarak sosial (social distancing) telah menghilangkan pendidikan lansung ke pendidikan jarak 
jauh. Situasi ini, meskipun disayangkan telah menunjukkan perlunya pembelajaran jarak jauh yang berkualitas (Dhawan, 2020).

Pembelajaran secara Virtual merupakan salah satu alternatif pilihan selama masa pandemic Covid 19. Pembelajaran virtual dilaksanakan dengan memanfaatkan perkembangan teknologi informasi dan komunikasi berupa kelas-kelas virtual asinkron dan singkron seperti Google classroom, Edmodo, Zoom, Google Meet, dll (Martin \& Parker, 2014). Terdapat banyak pilihan aplikasi dengan layanan kelas virtual yang memadai, diantaranya yang terkenal adalah Google Classroom, Edmodo, Schoology, Classdojo, dan Microsoft Classroom (Chan et al., 2015). Aplikasi-aplikasi tersebut menyediakan berbagai vitur dengan fleksibilitas yang baik yang memungkinkan guru dan siswa berbagi file konten pembelajaran baik berupa teks, audio, maupun video, serta dapat berkirim pesan, bertanya dan mengemukakan pendapat (Marlowe, 2012). Ruang penyimpanan yang besar juga sangat mendukung dalam pengarsipan konten pembelajaran sehingga pelajar dapat mengakses berulang kali sesuai kebutuhan mereka (Chan et al., 2015).

Dukungan teknologi pembelajaran yang telah diuraikan, ternyata belum dimanfaatkan secara optimal oleh guru di berbagai jenjang pendidikan. Fakta di lapangan menunjukkan penerapan kebijakan belajar dari rumah sebagai upaya memutus rantai penyebaran Covid-19 belum berjalan efektif dan melahirkan beberapa tantangan. Keterampilan digital guru dan siswa yang belum memadai turut menjadi variabel penyumbang hambatan pembelajaran online (Onyema et al., 2020).
Hasil wawancara dengan beberapa siswa dan guru matematika menunjukkan bahwa banyak siswa yang tidak mencapai pemahaman yang lengkap terhadap materi atau konten yang tersedia secara online dalam kelas virtual untuk beberapa topik tertentu yang sifatnya kompleks, misalnya topik bangun ruang. Konten pembelajaran bangun ruang yang biasa-biasa saja dan kebanyakan berupa teks bacaan menyebabkan siswa cenderung kesulitan membayangkan gambar tiga dimensi. Siswa membutuhkan interaksi dan penjelasan langsung secara verbal dari guru.

Sebagai rekomendasi dalam menyikapi persoalan tersebut, diperlukan konten pembelajaran yang berkualitas. Video pembelajaran merupakan salah satu pilihan yang tepat untuk pembelajaran virtual. Video pembelajaran lebih dapat mengakomodir gaya belajar siswa, karena dapat mengaktifkan fungsi indera pendengaran dan penglihatan, bahkan dapat juga divariasikan dengan penjelasan dalam bentuk animasi teks (Turyati et al., 2016; Busyaeri et al., 2016), serta dapat meciptakan pembelajaran berkualitas (Andi, 2011). Melalui akses internet, video pembelajaran yang tersedia secara online dapat menjangkau pelajar di seluruh dunia.

\begin{tabular}{rrrr}
\multicolumn{2}{c}{ Kesuksesan } & guru & dalam \\
mendesain & video & yang & efektif \\
merupakan & salah & satu & kunci
\end{tabular} keberhasilan dalam penerapan model VC. Untuk dapat menghasilkan video yang berkualitas, diperlukan dukungan media lain. Salah satu media yang cocok untuk topik bangun ruang adalah Geogebra. Geogebra (singkatan dari Geometri dan Algebra) dapat mendukung pembelajaran Geometri dan Aljabar dengan memfisualisakan objek 
menjadi lebih efektif dan efisien (Nur, 2016). Dengan pemanfaatan geogebra yang memiliki fasilitas tiga dimensi menjadikan gambar bangun ruang lebih presisi dan detail serta waktu menggambar menjadi lebih singkat. Fitur animasi pada geogebra dapat dimanfaatkan untuk mengekspose konstruksi bangun yang lebih kongkrit sehingga memudahkan siswa dalam mengidentifikasi ciri-ciri objek geometri dengan visualisasi lansung.

Berdasarkan penelitian-penelitian sebelumnya diperoleh hasil bahwa penggunaan video pembelajaran berbasis geogebra efektif terhadap kinerja akademik siswa dan dapat meningkatkan hasil belajar matematika siswa (Nurdin et al., 2019; Woolfitt, 2015; Zulnaidi \& Zamri, 2017; Ziden \& Abdul Rahman, 2013; Albaniah, 2014). Akan tetapi, dari penelitian-penelitian sebelumnya belum ada yang menggunakan video pembelajaran berbasis geogebra pada pembelajaran virtual. Oleh karena itu, dilakukan penelitian dengan judul "pengembangan video pembelajaran berbasis geogebra materi bangun ruang sisi datar pada pembelajaran virtual". Penelitian ini bertujuan untuk menghasilkan video pembelajaran berbasis geogebra materi bangun ruang sisi datar yang valid, praktis dan efektif yang digunakan pada pembelajaran virtual.

\section{METODE}

Penelitian ini termasuk dalam jenis penelitian pengembangan. Penelitian pengembangan ditandai dengan perancangan dan pengembangan produk dan selanjutnya dinilai kefektifannya setelah dilakukan uji coba (Purwanti, 2015). Produk yang akan dihasilkan dalam penelitian ini berupa video pembelajaran berbasis Geogebra materi bangun ruang sisi datar yang valid, praktis, dan efektif. Model pengembangan yang digunakan adalah model Plomp yang diadopsi dari Suarsana \& Mahayukti, (2013). Model Plomp terdiri atas 5 fase sebagai berikut: (1) investigasi awal; (2) desain; (3) konstruksi; (4) uji, evaluasi serta revisi produk; dan (5) implementasi. Subjek penelitian ini terdiri dari 24 orang siswa kelas VIII SMP Negeri 6 Buton Tengah Tahun Ajaran 2020/2021.

Instrumen pertama dalam penelitian ini adalah lembar validasi yang digunakan pada fase keempat. Penyusunan lembar validasi didasarkan pada dua komponen, yaitu komponen kelayakan isi dan komponen kelayakan tampilan (Ario, 2019). Komponen kelayakan isi terdiri atas 13 item penilaian, yaitu kesesuaian konten materi, kelengkapan konten, kedalaman konten, keakuratan konsep serta prosedur, kepresisian contoh, ketepatan soal, ketepatan istilah-istilah, keakuratan notasi serta simbol, kualitas uraian, kecermatan bahasa, kelugasan bahasa, sistematika penyajian, serta interaksi penyajian. Adapun komponen kalayakan tampilan disusun dari 8 (delapan) item penilaian, yaitu mutu gambar, mutu suara, mutu pencahayaan, keterbacaan tulisan, tata letak tulisan, interaksi serta komunikasi, fleksibilitas pemutaran video, serta kemenarikan video.

Instrumen kedua yang digunakan dalam penelitian ini, yaitu angket tanggapan siswa terhadap proses pembelajaran. Penyusunan angket didasarkan pada aspek penilaian antara lain fleksibilitas pemutaran video, kejelasan bacaan/tulisan pada video, kejelasan suara, kemudahan mengerti bahasa dalam video, kemudahan mengerti konten yang di informasikan, sistematika uraian konten, interaksi 
dalam uraian konten, kesesuian konten video dengan kurikulum, kedudukan video dalam mendukung proses belajar, kedudukan video selaku sumber belajar, kedudukan video dalam mengerti konten, kedudukan video dalam mengulangi pelajaran, serta kedudukan video buat kemudahan dalam belajar.

Intrumen ketiga, yaitu tes hasil belajar yang disusun dengan indikator: (1) siswa mampu memahami, memilah, dan menghitung luas permukaan dan volume bangun ruang sisi datar (kubus, balok, prisma, dan limas), dan (2) siswa dapat menerapkan konsep luas permukaan dan volume bangun ruang sisi datar dalam menyelesaikan permasalahan nyata.

Lembar validasi diberikan kepada 2 orang dosen dengan bidang keahlian masing-masing media pembelajaran dan pengajaran matematika. Adapun angket dan tes hasil belajar diberikan kepada siswa setelah proses pembelajaran (fase implementasi). Setiap pernyataan pada lembar validasi maupun angket menerapkan skala likert dengan kategori seperti pada Tabel 1.

Tabel 1. Skor lembar validasi dan angket

\begin{tabular}{cc}
\hline Skor & Kriteria \\
\hline 4 & Sangat baik \\
3 & Baik \\
2 & Cukup \\
1 & Kurang \\
0 & Sangat kurang \\
\hline
\end{tabular}

Sumber: Ali dalam (Ario, 2019)

Analisis validitas dan praktikalitas video dihitung dengan rumus hasil rating (HR) yang diadaptasi dari (Setiyani et al., 2020) sebagai berikut.

$$
\mathrm{HR}=\frac{\text { Skor penilai }}{\text { Skor maksimal }} \times 100 \%
$$

Hasil perhitungan diinterpretasikan menurut kriteria pada Tabel 2. Video dikatakan valid dan praktis apabila hasil rating berkriteria minimal baik.

Tebal 2. Kriteria hasil rating

\begin{tabular}{cc}
\hline Hasil Rating (\%) & Kriteria \\
\hline $84<\mathrm{HR} \leq 100$ & Sangat baik \\
$68<\mathrm{HR} \leq 84$ & Baik \\
$52<\mathrm{HR} \leq 68$ & Cukup baik \\
$36<\mathrm{HR} \leq 52$ & Kurang \\
$20 \leq \mathrm{HR} \leq 36$ & Sangat kurang \\
\hline
\end{tabular}

Efektifitas video ditentukan berdasarkan nilai Kriteria Ketuntasan Minimal (KKM) dengan rumus sebagai berikut.

$$
\mathrm{HR}=\frac{\mathrm{X}}{\mathrm{N}} \times 100 \%
$$

Keterangan :

$\mathrm{X}=$ jumlah siswa yang memperoleh nilai $\geq 70(\mathrm{KKM})$

$\mathrm{N}=$ jumlah peserta/siswa

Video disebut efektif apabila hasil rating memenuhi kriteria minimal baik mengacu pada kriteria Tabel 2.

\section{HASIL DAN PEMBAHASAN}

Produk atau hasil pengembangan dalam riset ini berupa video pembelajaran dengan konten bangun ruang sisi datar. Dalam memproduksi video pembelajaran melibatkan 5 fase sebagai berikut: (1) investigasi awal, (2) desain, (3) konstruksi, (4) uji, evaluasi, revisi, (5) implementasi.

\section{Fase Investigasi Awal}

Fase investigasi awal dimaksudkan untuk menentukan masalah dasar dalam pembelajaran virtual sebagai acuan dalam melakukan pengembangan video pembelajaran. Kegiatan yang dilakukan meliputi wawancara dengan guru dan siswa, telaah kurikulum dan materi ajar, serta analisis kebutuhan pembelajaran virtual. 
Dari hasil wawancara dengan guru matematika dan siswa diperoleh bahwa banyak siswa yang tidak mencapai pemahaman yang lengkap terhadap materi atau konten yang tersedia secara online dalam kelas virtual untuk beberapa topik tertentu yang sifatnya kompleks, misalnya topik bangun ruang. Konten pengajaran bangun ruang yang konvensional dan umumnya berbentuk bacaan mengakibatkan siswa cenderung kesukaran mencitrakan gambar berbentuk ruang atau tiga dimensi. Siswa menghabiskan banyak waktu untuk membayangkan gambar berbentuk ruang. Siswa membutuhkan sajian konten materi yang interaktif dan komunikatif.

Telaah kurikulum dan materi ajar dimaksudkan untuk mendefinisikan kebutuhan pembelajaran bangun ruang sisi datar dalam kelas virtual dengan membedah kompetensi dasar dan indikator pencapaian kompetensi yang menjadi tujuan pembelajaran. Kompetensi dasarnya adalah: (1) siswa mampu memamhami, memilah, dan menghitung luas permukaan dan volume bangun ruang sisi datar (kubus, balok, prisma, dan limas) dan (2) siswa dapat menerapkan konsep luas permukaan dan volume bangun ruang sisi datar dalam memecahkan dan menyelesaikan permasalahan nyata. Adapun indikator pencapaian kompetensi materi bangun ruang sisi datar, yaitu siswa mampu menemukan pola tertentu untuk mengetahui turunan rumus luas permukaan dan volume kubus, balok, prima dan limas serta dapat menerapkannya dalam penyelesaian masalah yang berkaitan dengan luas dan volume.

Analisis terhadap pembelajaran virtual di SMPN 6 Buton Tengah ditemukan bahwa pembelajaran menggunakan aplikasi google classroom. Materi yang dibagikan pada classroom berbentuk slide ppt dan cenderung copy paste dari buku paket. Interaksi kelas masih minim dan umpan balik belum efektif.

Hasil investigasi awal tersebut menjadi justifikasi perlunya konten pembelajaran disajikan dalam bentuk video yang interaktif dan komunikatif. Dengan video tersebut siswa dalam belajar tidak hanya mengandalkan indra visual tetapi juga auditorial. Oleh karena itu, pada fase ini ditetapkan produk yang akan dikembangkan adalah video pembelajaran.

\section{Fase Desain}

Setelah mengetahui kebutuhan pembelajaran virtual, fase selanjutnya adalah membuat kerangka rancangan. Kegiatan yang dilakukan pada fase ini meliputi membuat konsep rancangan video, memilah materi ke dalam beberapa video, memperhitungkan durasi waktu setiap video, membuat umpan balik, dan mempersiapkan aplikasi dan peralatan yang akan digunakan. Selain itu, pada fase ini juga dirancang instrument penelitian yang dibutuhkan antara lain: lembar validasi, angket, dan tes hasil belajar. Rancangan yang dihasilkan pada fase ini ialah sebagai berikut.

1. Materi bangun ruang sisi datar dipilah menjadi empat bagian berdasarkan sub topik, yaitu kubus, balok, prisma, dan limas. Setiap bagian materi akan dimuat dalam video yang berbeda.

2. Setiap sub topik dibuatkan dalam dua video dengan ketentuan video pertama memuat konten tujuan pembelajaran, isi atau materi, dan contoh soal, video kedua berisi tutorial pemecahan masalah dan contoh penerapan dalam kehidupan 
sehari-hari. Sehingga total video yang akan diproduksi adalah delapan video.

3. Desain slide ppt yang berisi animasi teks terkait materi. Slide ini akan digunakan sebagai latar video dengan satu video memerlukan satu slide.

4. Animasi rancang bangun atau bongkar pasang untuk masingmasing gambar kubus, balok, prisma dan limas berbasis geogebra yang mengekspos sudut, rusuk, sisi, jaring-jaring hingga terbentuknya bangun ruang.

5. Durasi waktu buat tiap video dirancang tidak melebihi 30 menit, agar siswa tidak jenuh saat menonton. Video yang berdurasi pendek juga memudahkan siswa dalam memutar ulang bagian-bagian yang belum jelas.

6. Aplikasi yang akan digunakan untuk memproduksi video ialah aplikasi screen capture Open Broadcaster Software (OBS), aplikasi geogebra, dan microsoft power point. Adapun perangkat yang dibutuhkan, yaitu meja dan kursi, laptop, kamera, lampu pencahayaan, latar green screen, dan mikrofon. Perangkatperangkat tersebut ditata sedemikian rupa dalam sebuah ruangan produksi sehingga siap pakai.

\section{Fase Konstruksi}

Pade fase ini dilakukan konstruksi video berdasarkan hasil rancangan pada fase sebelumnya. Video dibuat dengan merekam aktivitas layar laptop dan suara instruktur secara real time menggunakan OBS. Pada aplikasi OBS sudah diatur menggunakan dua scene, dimana scene1 menggunakan latar slide ppt dan scene2 menggunakan latar geogebra seperti yang tersaji pada Gambar 1. Instruktur menjalankan OBS untuk merekam aktifitas dalam menerangkan materi secara bergantian pada scene1 dan scene2 dengan memanfaatkan menu transisi. Selanjutnya dilakukan pengeditan pada hasil rekaman untuk memperkecil ukuran file agar memudahkan diupload di Youtube dan mempemudah akses siswa terhadap video. Selain itu, dilakukan juga editing audio untuk menghilangkan noise agar suara jernih dan bebas dari gangguan suara luar.

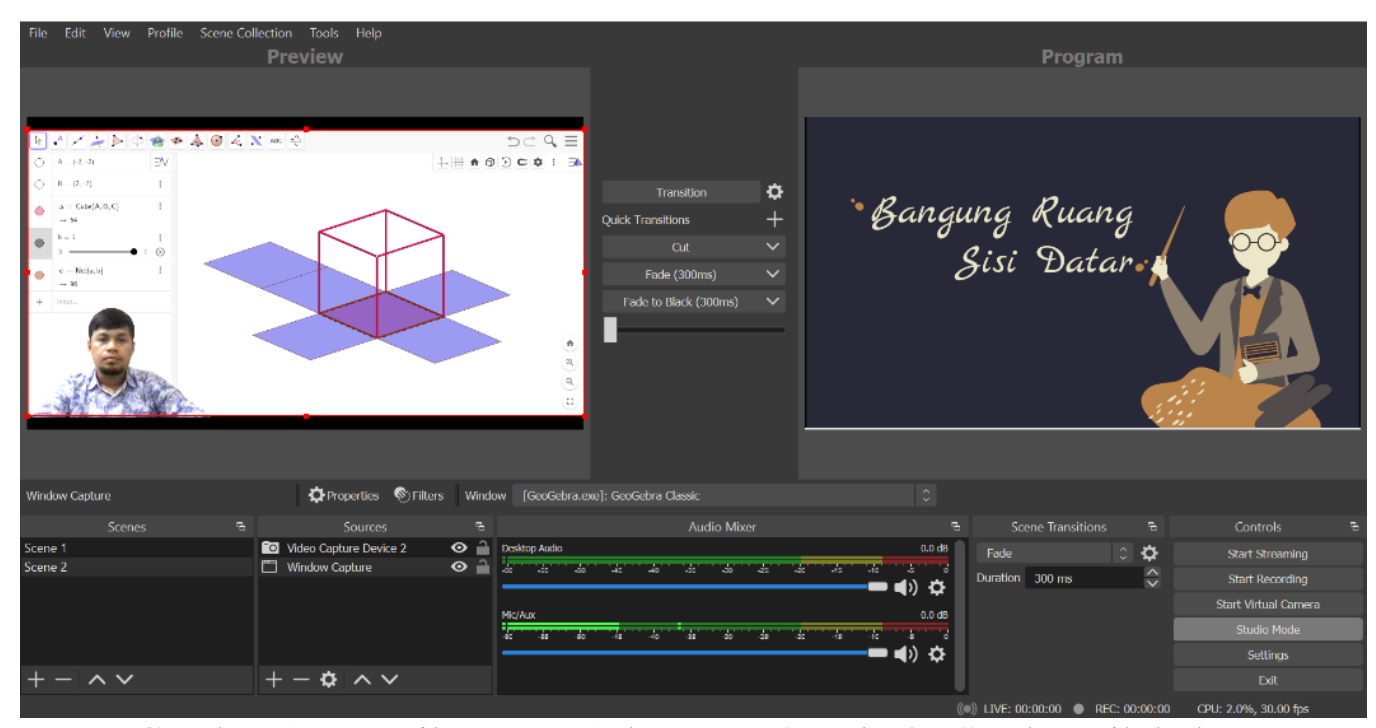

Gambar 1. Tampilan scene1 dan scene2 pada OBS sub topik kubus 
Fase Uji, Evaluasi, dan Revisi Produk

Fase uji produk, evaluasi, dan revisi (jika ada) bertujuan untuk menilai kevalidan video pembelajaran. Video divalidasi oleh ahli yang terdiri dari dosen pengampu media pembelajaran dan dosen pengampu pengajaran matematika. Delapan video diputar secara berurutan dihadapan kedua validator yang sebelumnya sudah diberikan lembar validasi. Kedua validator memberikan penilaian secara obyektif berdasarkan aspek-aspek penilaian dalam lembar validasi. Hasil analisis validitas video pembelajaran disajikan pada Tabel 3 .

Tabel 3. Hasil analisis validitas produk

\begin{tabular}{|c|c|c|c|c|}
\hline \multirow[t]{2}{*}{ Validator } & \multicolumn{2}{|c|}{$\begin{array}{c}\text { Jumlah } \\
\text { skor }\end{array}$} & \multicolumn{2}{|c|}{$\begin{array}{c}\text { Hasil } \\
\text { rating }(\%)\end{array}$} \\
\hline & $\mathbf{a}$ & b & $\mathbf{a}$ & b \\
\hline Validator 1 & 49 & 31 & 94,2 & 96,8 \\
\hline Validator 2 & 48 & 32 & 92,3 & 100 \\
\hline Rata-rata & 48,5 & 31,5 & 93,3 & 98,4 \\
\hline
\end{tabular}

Keterangan:

a : Kelayakan isi

b : Kelayakan tampilan

Tabel 3 dapat dijelaskan bahwa untuk aspek kelayakan isi mendapatkan penilaian dengan jumlah skor 49 dari validator 1 dan 48 dari validator 2 dengan skor maksimal 52. Rata-rata hasil rating dari kedua validator adalah. 93,3\% masuk dalam kategori sangat baik. Untuk aspek kelayakan tampilan validator 1 memberikan skor 31 dan validator 2 memberikan skor 32 dari skor maksimal 32. Dengan menghitung hasil rating diperoleh rata-rata hasil rating dari kedua validator adalah 98,4\% berada pada kriteria sangat baik. Dengan demikian dapat disimpulkan bahwa video pembelajaran materi bangun ruang sisi datar berbasis geogebra dinyatakan valid dengan kriteria sangat baik.
Keterpenuhan aspek validitas terhadap produk pengembangan menunjukkan bahwa produk layak untuk diujicobakan. Hal ini didukung pula dengan catatan dari kedua validator yang bernada positif dan tidak ada koreksi yang berarti. Dengan demikian video pembelajaran lansung diujicobakan tanpa dilakukan revisi.

\section{Fase Implementasi}

Fase implementasi yaitu fase penerapan video pada proses pembelajaran untuk mengetahui kepraktisan dan keefektifan video. Proses pembelajaran dilakukan secara virtual di SMPN 6 Buton Tengah melalui perpaduan aplikasi google classroom dan WA grup. Video pembelajaran dibagikan di classroom dan di WA grup menjelang jadwal pembelajaran. Siswa diberi kesempatan menyimak video, selanjutnya dilakukan diskusi dan tanya jawab melalui WA grup. Kegiatan diskusi dan tanya jawab di WA grup sebagian besar disampaikan dalam bentuk voice note. Menjelang akhir pembelajaran siswa diminta memberikan kesimpulan terhadap materi pembelajaran dalam bentuk voice note di WA grup. Tahap terakhir mengerjakan umpan balik yang sudah dibagikan di classroom dan menyerahkan hasil pekerjaan di classroom sebelum kelas berakhir. Kegiatan pembelajaran berjalan dengan lancar. Siswa antusias bertanya dan menjawab pertanyaan.

Setelah kegiatan uji coba produk selesai, siswa diminta mengisi angket dalam bentuk google form yang telah diposting di classroom secara jujur. Pertemuan terakhir siswa diminta mengerjakan tes pilihan ganda yang ada di classroom. Skor angket selanjutnya direkap untuk dianalisis. Hasil analisis skor angket disajikan pada Tabel 4. 
DOI: https://doi.org/10.24127/ajpm.v10i4.4198

Tabel 4. Deskripsi hasil rating skor angket

\begin{tabular}{lc}
\hline Deskripsi & Nilai \\
\hline Jumlah responden & 24 orang \\
Hasil rating minimum & $84,62 \%$ \\
Hasil rating maksimum & $98,08 \%$ \\
Rata-rata hasil rating & $93,35 \%$ \\
\hline
\end{tabular}

Dari Tabel 4 diperoleh hasil rating skor angket yaitu, hasil rating minimum $84,62 \%$, hasil rating maksimum $98,08 \%$, dan rata-rata hasil rating 93,35\%. Hasil ini menunjukkan video pembelajaran materi bangun ruang sisi datar berbasis geogebra memenuhi kriteria kepraktisan dengan kategori sangat baik.

Selanjutnya dilakukan penilaian pada aspek keefektifan video menggunakan data hasil belajar. Deskripsi hasil belajar disajikan pada Tabel 5. Tabel 5 menginformasikan bahwa minimum hasil belajar siswa adalah 65,00. Nilai ini berada di bawah KKM. Terdapat dua orang siswa yang memperoleh nilai di bawah KKM. Sedangkan maksimum hasil belajar siswa adalah 95,00. Rata-rata hasil belajar siswa adalah 80,63. Dengan menghitung hasil rating diperoleh hasil 91,67\% masuk dalam kriteria sangat baik. Dengan demikian, video pembelajaran dinyatakan efektif dengan kategori sangat baik.

Tabel 5. Deskripsi hasil belajar

\begin{tabular}{cc}
\hline Deskripsi & Nilai \\
\hline Jumlah peserta & 24 orang \\
Nilai minimum & 65,00 \\
Nilai maksimum & 95,00 \\
Mean & 80,63 \\
Standar deviasi & 8,25 \\
\hline
\end{tabular}

Hasil penelitian ini relevan dengan temuan Zulnaidi \& Zamri, (2017) bahwa video pembelajaran berbasis geogebra efektif terhadap kemampuan pemahaman konsep dan hasil belajar matematika. Sejalan dengan hasil tersebut, Nurdin et al., (2019) menyimpulkan bahwa pemanfaatan media video pembelajaran berbasis geogebra dalam proses pembelajaran dapat meningkatkan hasil belajar matematika siswa.

Potret hasil belajar siswa yang baik tersebut telah mengkonfirmasi peran penting video pembelajaran dalam lingkungan virtual. Video pembelajaran yang terarsip dengan baik dalam google classroom memudahkan siswa untuk mengakses dan belajar kapan saja yang mereka inginkan. Durasi video yang relatif singkat membuat siswa mudah memutar secara berulang bagian-bagian materi yang dianggap masih kurang sehingga menambah pemahaman. Keunggulan tersebut menjadi magnet yang memikat siswa untuk antusias belajar. Dengan video siswa dapat memaksimalkan belajar melalui indra visual dan auditorial, pembelajaran menjadi lebih bermakna dan menyenangkan yang dapat mendukung pencapaian tujuan pembelajaran. Menurut Purwanti, (2015) pengalaman belajar siswa yang baik dari penggunaan video menumbuhkan persepsi positif dan meningkatkan motivasi belajar siswa. Video yang dibangun dengan benar memiliki kekuatan untuk memahamkan siswa dibanding bahan bacaan teks (Setiyani et al., 2020).

Khusus untuk materi geometri seperti bangun ruang, penggunaan video berbasis geogebra yang memiliki fitur animasi dan gerakan tentang rancang bangun serta dilengkapi dengan fasilitas tiga dimensi dapat memudahkan siswa dalam memahami konsep bangun ruang melalui visualisasi yang lebih dinamis sehingga berdampak terhadap capaian hasil belajar. Sebagimana telah 
dikemukan oleh Isharyadi \& Ario, (2019); Nur, (2016) bahwa software geogebra sangat membantu dalam pembelajaran geometri karena didukung dengan fasilitas animasi dalam berbagai arah sehingga objek geometri nampak jelas dan amatan siswa menjadi lebih efektif.

\section{KESIMPULAN DAN SARAN}

Video pembelajaran yang dikembangkan dalam penelitian ini memenuhi tiga aspek penilaian kualitas, yaitu valid, praktis dan efektif. Video pembelajaran yang diposting dalam google classroom dengan durasi yang relatif singkat memudahkan siswa untuk belajar dan mengulang bagian-bagian pelajaran yang dianggap kurang. Penggunaan video sebagai salah satu sumber belajar online menjadikan pembelajaran lebih konkrit dan memotivasi siswa untuk belajar. Dukungan aplikasi geogebra dalam produksi video membantu siswa dalam memahami konsep bangun ruang karna siswa dapat memvisualisasikan gambar tiga dimensi secara efektif dan efisien.

Video pembelajaran berbasis geogebra dapat menjadi rekomendasi alternatif sumber belajar secara virtual terutama materi geometri dan materi lain yang membutuhkan visualiasi dan penalaran spasial. Pengembangan video berbasis geogebra dapat diperluas untuk topik lain yang relevan dan diuji keefektifannya lebih luas dalam kelaskelas virtual.

\section{UCAPAN TERIMA KASIH}

Terima kasih kami sampaikan kepada DRPM Kemdikbud-Ristek yang telah membiayai penelitian ini melalui skim Penelitian Dosen Pemula 2021.

\section{DAFTAR PUSTAKA}

Albaniah, T. (2014). Hubungan Penggunaan Media Video Pembelajaran Dengan Hasil Belajar Siswa Pada Mata Pelajaran Matematika Kelas Iv Sdn 76/1 Sungai Buluh. Artikel Ilmiah.

Andi, P. (2011). Panduan Kreatif Membuat Bahan Ajar Inovatif: Menciptakan Metode Pembelajaran yang Menarik dan Menyenangkan. In Diva Press.

Ario, M. (2019). Pengembangan Video Pembelajaran Materi Integral Pada Pembelajaran Flipped Classroom. AKSIOMA: Jurnal Program Studi Pendidikan Matematika, 8(1), 20-31. https://doi.org/10.24127/ajpm.v8i 1.1709

Busyaeri, A., Udin, T., \& Zaenudin, A. (2016). Pengaruh Penggunaan Video Pembelajaran Terhadap Peningkatan Hasil Belajar Mapel Ipa Di Min Kroya Cirebon. Al Ibtida: Jurnal Pendidikan Guru MI, 3(1). https://doi.org/10.24235/al.ibtida.s nj.v3i1.584

Chan, N. N., Walker, C., \& Gleaves, A. (2015). An exploration of students' lived experiences of using smartphones in diverse learning contexts using a hermeneutic phenomenological approach. Computers and Education.

https://doi.org/10.1016/j.compedu .2014.11.001

Dhawan, S. (2020). Online Learning: A Panacea in the Time of COVID19 Crisis. Journal of Educational Technology Systems. https://doi.org/10.1177/00472395 20934018

Isharyadi, R., \& Ario, M. (2019). 
DOI: https://doi.org/10.24127/ajpm.v10i4.4198

Praktikalitas dan Efektivitas Modul Geometri Transformasi Berbantuan Geogebra bagi Mahasiswa Pendidikan Matematika. Jurnal Absis : Jurnal Pendidikan Matematika Dan Matematika, 1(2). https://doi.org/10.30606/absis.v1i 2.93

Marlowe, C. A. (2012). The Effect Of The Flipped Classroom On Student Achievement And Stress. Journal of Chemical Information and Modeling.

Martin, F., \& Parker, M. (2014). Use of Synchronous Virtual Classrooms: Why, Who, and How? Journal of Online Learning and Teaching, 10(2).

Nur, I. M. (2016). Pemanfaatan Program Geogebra dalam Pembelajaran Matematika. Jurnal Matematika Dan Pendidikan Matematika, 5(1). https://doi.org/10.1038/oncsis.201 6.1

Nurdin, E., Ma'aruf, A., Amir, Z., Risnawati, R., Noviarni, N., \& Azmi, M. P. (2019). Pemanfaatan video pembelajaran berbasis Geogebra untuk meningkatkan kemampuan pemahaman konsep matematis siswa SMK. Jurnal Riset Pendidikan Matematika. https://doi.org/10.21831/jrpm.v6i 1.18421

Onyema, E. M., Eucheria, N. C., Obafemi, F. A., Sen, S., \& Atonye, F. G. (2020). Impact of Coronavirus Pandemic on Education. Journal of Education and Practice, 11.

Purwanti, B. (2015). Pengembangan Media Video Pembelajaran Matematika dengan Model Assure. Jurnal Kebijakan Dan Pengembangan Pendidikan, 3(1).
Setiyani, Putri, D. P., Ferdianto, F., \& Fauji, S. H. (2020). Designing a digital teaching module based on mathematical communication in relation and function. Journal on Mathematics Education, 11(2). https://doi.org/10.22342/jme.11.2. 7320.223-236

Suarsana, I. M., \& Mahayukti, G. A. (2013). Pengembangan E-Modul Berorientasi Pemecahan Masalah Untuk Meningkatkan Keterampilan Berpikir Kritis Mahasiswa. Jurnal Nasional Pendidikan Teknik Informatika (JANAPATI), 2(3). https://doi.org/10.23887/janapati. v2i3.9800

Turyati, Muchtarom, M., \& Winarno. (2016). Pengaruh penggunaan media video edukasi terhadap hasil belajar pkn siswa kelas Vii smp negeri 2 gondangrejo. $P K n$ Progresif, 11(1).

Woolfitt, Z. (2015). The effective use of video in higher education. Lectoraat Teaching, Learning and Technology. Inholland University of Applied Sciences, October.

Ziden, A. A., \& Abdul Rahman, M. F. (2013). The effectiveness of webbased multimedia applications simulation in teaching and learning. International Journal of Instruction, 6(2).

Zulnaidi, H., \& Zamri, S. N. A. S. (2017). The effectiveness of the geogebra software: The intermediary role of procedural knowledge on students' conceptual knowledge and their achievement in mathematics. Eurasia Journal of Mathematics, Science and Technology Education, 13(6). https://doi.org/10.12973/eurasia.2 017.01219a 